\title{
Treatment of patients with systemic-onset juvenile idiopathic arthritis with tacrolimus
}

\author{
DONGDONG WANG $^{1 *}, \mathrm{XIAO} \mathrm{CHEN}^{2 *}$ and $\mathrm{ZHIPING} \mathrm{LI}{ }^{1}$ \\ ${ }^{1}$ Department of Pharmacy, Children's Hospital of Fudan University, Shanghai 201102; \\ ${ }^{2}$ Department of Pharmacy, The People's Hospital of Jiangyin, Jiangyin, Jiangsu 214400, P.R. China
}

Received June 9, 2018; Accepted January 10, 2019

DOI: 10.3892/etm.2019.7174

\begin{abstract}
Previously, few studies have reported treatment with tacrolimus (TAC) for patients with systemic-onset juvenile idiopathic arthritis (SOJIA). The aim of the current study was to investigate the effect of TAC on patients with SOJIA. Data were collected from the beginning of treatment with TAC to the 12-month endpoint, which was defined as the last follow-up. Clinical characteristics included sex, age, duration of the disease, TAC dose, erythrocyte sedimentation rate $(\mathrm{ESR}), \mathrm{C}$ reactive protein $(\mathrm{CRP})$, hemoglobin $(\mathrm{Hb})$, platelet (PLT) and white blood cell (WB) levels, prednisolone (PDN) dose and interleukin-6 (IL-6) expression. The baseline characteristics of the patients were: ESR, $67.8 \pm 18.7 \mathrm{~mm} / \mathrm{h}$; CRP, $128.0 \pm 38.9 \mathrm{mg} / \mathrm{l} ; \mathrm{Hb}, 108.7 \pm 13.7 \mathrm{~g} / \mathrm{l}$; PLT, 416.8 $\pm 90.1 \times 10^{9} / 1$; WB, $26.0 \pm 10.2 \times 10^{9} / 1$; PDN dose, $49.0 \pm 17.1 \mathrm{mg} /$ day. Following 12 months of treatment with TAC, ESR, CRP, PLT and WB levels, and the dose of PDN required for the treatment of patients with SOIJA were all decreased compared with the baseline values. No serious adverse reactions were reported. Therefore, TAC could be an effective treatment for SOJIA.
\end{abstract}

\section{Introduction}

Systemic-onset juvenile idiopathic arthritis (SOJIA) is a severe and distinctive type of juvenile arthritis (1). The pathophysiology of systemic manifestations of SOJIA appears to be associated with continuous activation of innate immune pathways, resulting in dysregulated production of proinflammatory cytokines (2). For example, interleukin (IL)-1 $\beta(3,4)$ and IL-6 (5) have been indicated to be important cytokines in

Correspondence to: Professor Zhiping Li, Department of Pharmacy, Children's Hospital of Fudan University, 399 Wanyuan Road, Shanghai 201102, P.R. China

E-mail: zplifudan@126.com

*Contributed equally

Key words: treatment, systemic-onset juvenile idiopathic arthritis, tacrolimus the pathogenesis of SOJIA. Therefore, targeting IL-1 and IL-6 has become a treatment strategy for SOJIA $(6,7)$.

Tacrolimus (TAC) is a relatively novel immunosuppressive drug, which inhibits the transcription of the early activation genes of IL-2 and suppresses the production of tumor necrosis factor (TNF)- $\alpha$, IL-1 $\beta$ and IL- 6 through T cell activation $(8,9)$. In addition to being used during transplantation, TAC has also been used without serious adverse effects for treating refractory nephrotic syndrome $(10,11)$, lupus nephritis (12), and rheumatoid arthritis $(8,9)$. However, few studies have reported the use of treatment with TAC in patients with SOJIA. The aim of the current study was to investigate the effect of TAC on SOJIA.

\section{Patients and methods}

Patients. The current data were obtained retrospectively from medical records of patients diagnosed with SOJIA. All patients were under 18 years old and received TAC treatment at the Children's Hospital of Fudan University (Shanghai, China) between January 2015 and January 2018.

Patient characteristics and outcomes. Data were collected from the beginning of TAC treatment for 12 months, with the 12-month endpoint defined as the last follow-up. Clinical characteristics including sex, age, duration of the disease, TAC dose, erythrocyte sedimentation rate (ESR), $C$ reactive protein (CRP), hemoglobin (Hb), platelet (PLT) and white blood cell (WB) levels, prednisolone (PDN) dose and interleukin-6 (IL-6) expression at the beginning of TAC treatment ( 0 months) and following treatment with TAC for 6 months and 12 months were obtained from medical records retrospectively.

Statistical analysis. Data are presented as the mean \pm standard error. Statistical analyses were performed using the General Linear Model for repeated measurement. $\mathrm{P}<0.05$ was considered to indicate a statistically significant difference. The statistical analysis was performed using SPSS software (version 13.0; SPSS, Inc., Chicago, IL, USA).

\section{Results}

Summary of clinical characteristics. Clinical characteristics are summarized in Table I. A total of 6 Chinese patients with 


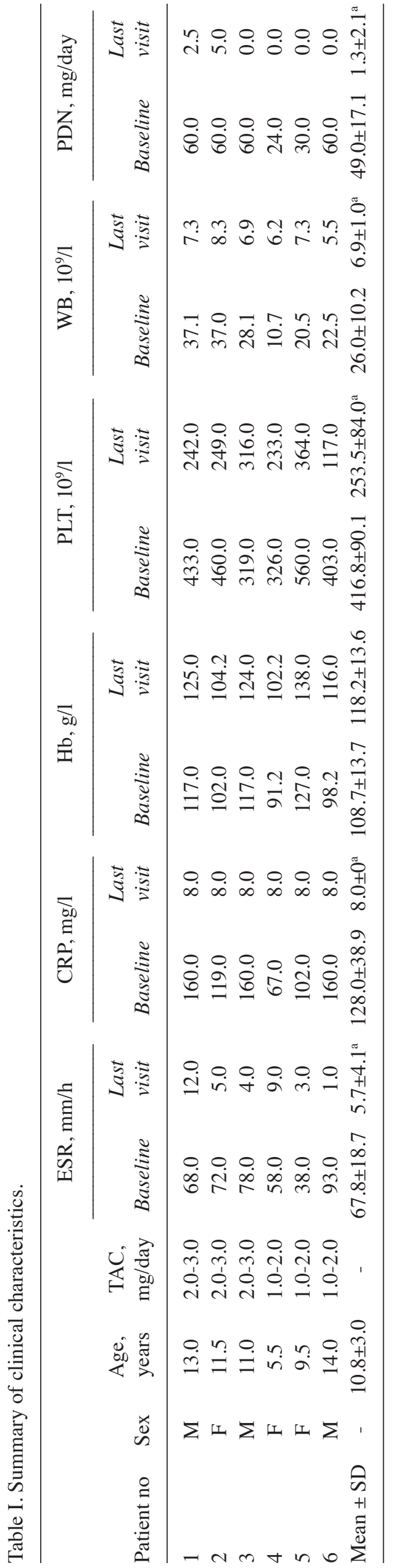

Table II. Alterations in IL-6 expression levels among the 6 patients.

\begin{tabular}{lcc}
\hline & \multicolumn{2}{c}{ IL-6, pg/ml } \\
\cline { 2 - 3 } Patient no. & $\begin{array}{c}\text { Prior to treatment } \\
\text { with TAC }\end{array}$ & $\begin{array}{c}\text { Following treatment with } \\
\text { TAC for 12 months }\end{array}$ \\
\hline 1 & 265.90 & 15.04 \\
2 & 50.00 & 8.70 \\
3 & 112.90 & 9.05 \\
4 & $>1000.00$ & 1.92 \\
5 & 198.00 & 9.13 \\
6 & 317.80 & 2.35 \\
Mean \pm SD & $324.10 \pm 345.23$ & $7.70 \pm 4.91^{\mathrm{a}}$ \\
\hline
\end{tabular}

IL-6, interleukin 6; TAC, tacrolimus; SD, standard deviation. ${ }^{\mathrm{a}} \mathrm{P}<0.05$ vs. baseline.

SOJIA, including 3 males and 3 females from Children's Hospital of Fudan University, were included for studying the effect of TAC on SOJIA. Patient ages ranged from 5.5 to 14.0 years old (mean, 10.8 \pm 3.0 years), and the duration of disease ranged from 1.1 to 5.0 years. During follow-up time, TAC doses were 1.0-3.0 mg/day. The baseline characteristics of the patients were: ESR, $67.8 \pm 18.7 \mathrm{~mm} / \mathrm{h}$; CRP, $128.0 \pm 38.9 \mathrm{mg} / \mathrm{l} ; \mathrm{Hb}, 108.7 \pm 13.7 \mathrm{~g} / \mathrm{l} ;$ PLT, $416.8 \pm 90.1 \times 10^{9} / 1$; WB, $26.0 \pm 10.2 \times 10^{9} / 1 ;$ PDN dose, $49.0 \pm 17.1 \mathrm{mg} /$ day.

Changes in ESR and CRP level following treatment with $T A C$. ESR and CRP level were significantly lower at 6 and 12 months compared with 0 months (all $\mathrm{P}<0.05$; Fig. 1). These results indicated that TAC could significantly downregulate the high ESR and CRP level in SOJIA.

Changes in Hb, PLT and WB levels following treatment with $T A C$. Hb level significantly increased at 6 months of treatment with TAC compared with the baseline level $(\mathrm{P}<0.05$; Fig. 2A and B). However, following treatment with TAC for 12 months, the $\mathrm{Hb}$ level decreased compared with the value at 6 months $(\mathrm{P}<0.05)$. PLT and WB levels significantly decreased after 6 and 12 months of treatment with TAC compared with baseline (all $\mathrm{P}<0.05$; Fig. 2C-F). These results indicated that administration of TAC significantly decreased the levels of PLT and WB in patients with SOJIA. However, the level of $\mathrm{Hb}$ increased at 6 months, followed by a decrease at 12 months of treatment.

Changes in PDN dose following treatment with TAC. Following treatment with TAC for 6 and 12 months, PDN dose was decreased compared with the baseline $(\mathrm{P}<0.05$; Fig. 3$)$, indicating that treatment with TAC reduced the dose of PDN required for the treatment of patients with SOJIA.

Changes in the expression levels of IL-6 following treatment with TAC. Following treatment with TAC for 12 months, the expression levels of IL-6 decreased significantly compared with the baseline level (Table II). These results indicated that 

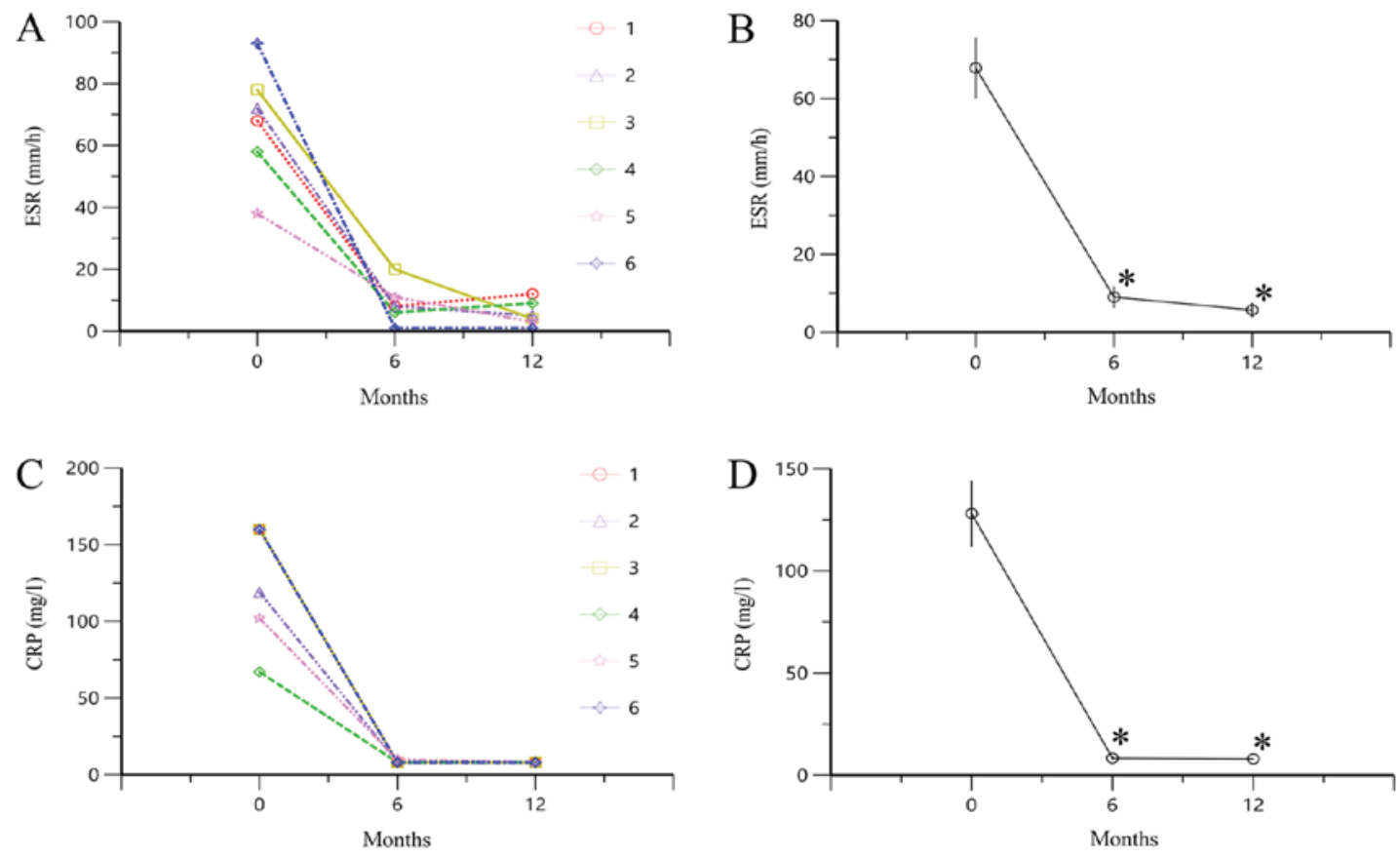

Figure 1. Alterations in ESR and CRP level following treatment with TAC. (A) ESR of each patient. (B) Mean \pm SE values of ESR. (C) CRP levels of each patient. (D) Mean \pm SE values of CRP levels. " $\mathrm{P}<0.05$ vs. 0 months. ESR, erythrocyte sedimentation rate; $\mathrm{CRP}, \mathrm{C}$ reactive protein; TAC, tacrolimus; 0 months, data obtained prior to treatment with TAC; 6 months, data obtained at 6 months of treatment with TAC; 12 months, data obtained at 12 months of treatment with TAC.
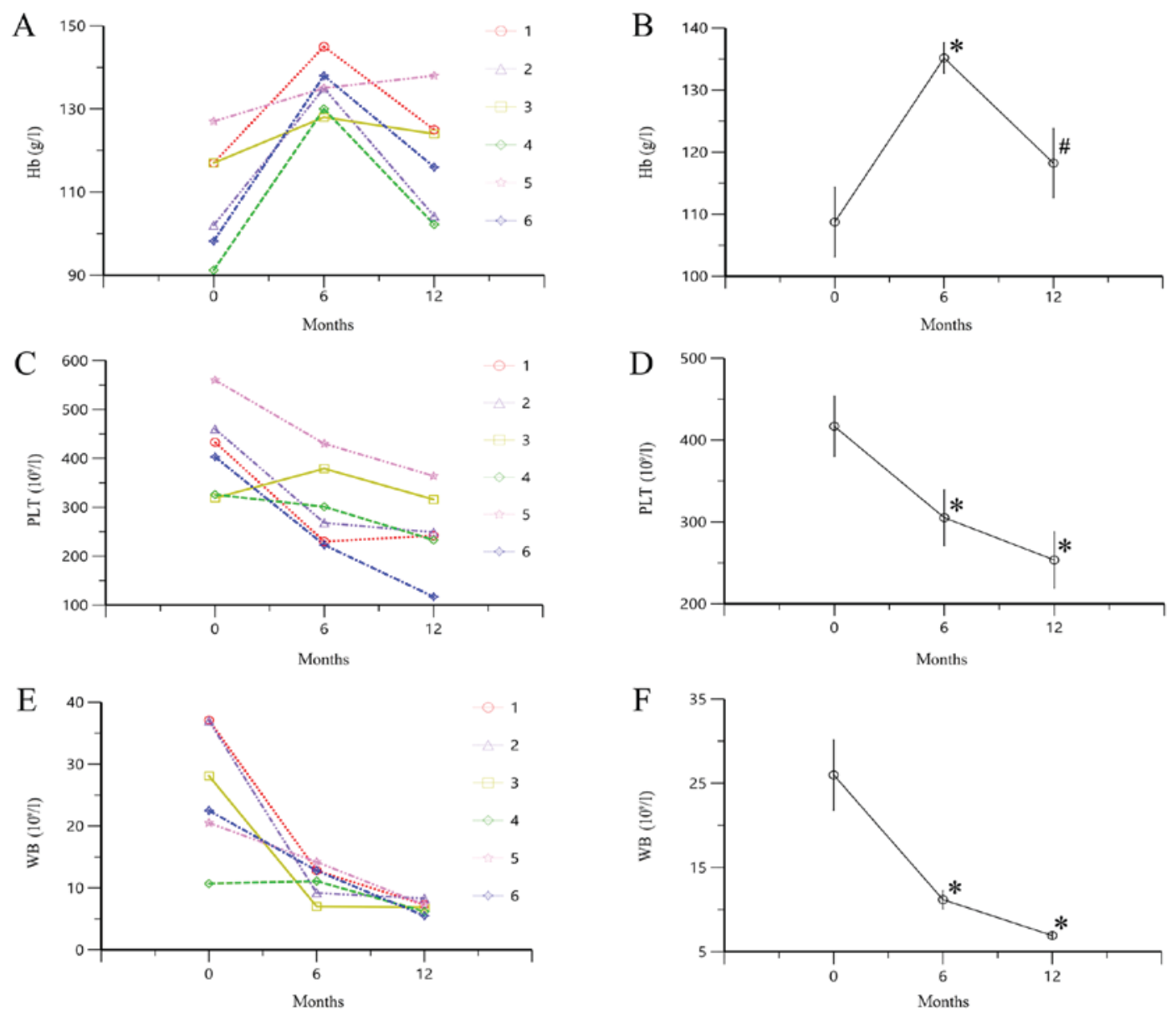

Figure 2. Changes in Hb, PLT and WB levels following treatment with TAC. (A) Alterations in Hb levels of each patient. (B) Mean $\pm \mathrm{SE}$ values of $\mathrm{Hb}$ levels. (C) Alterations in PLT levels of each patient. (D) Mean \pm SE values of PLT levels. (E) Alterations in WB levels of each patient. (F) Mean \pm SE values of WB levels. ${ }^{*} \mathrm{P}<0.05$ vs. 0 months and ${ }^{\text {"P}} \mathrm{P}<0.05$ vs. 6 months. TAC, tacrolimus; Hb, hemoglobin; PLT, platelet; WB, white blood cell; 0 months, data obtained prior to treatment with TAC; 6 months, data obtained at 6 months of treatment with TAC; 12 months, data obtained at 12 months of treatment with TAC. 

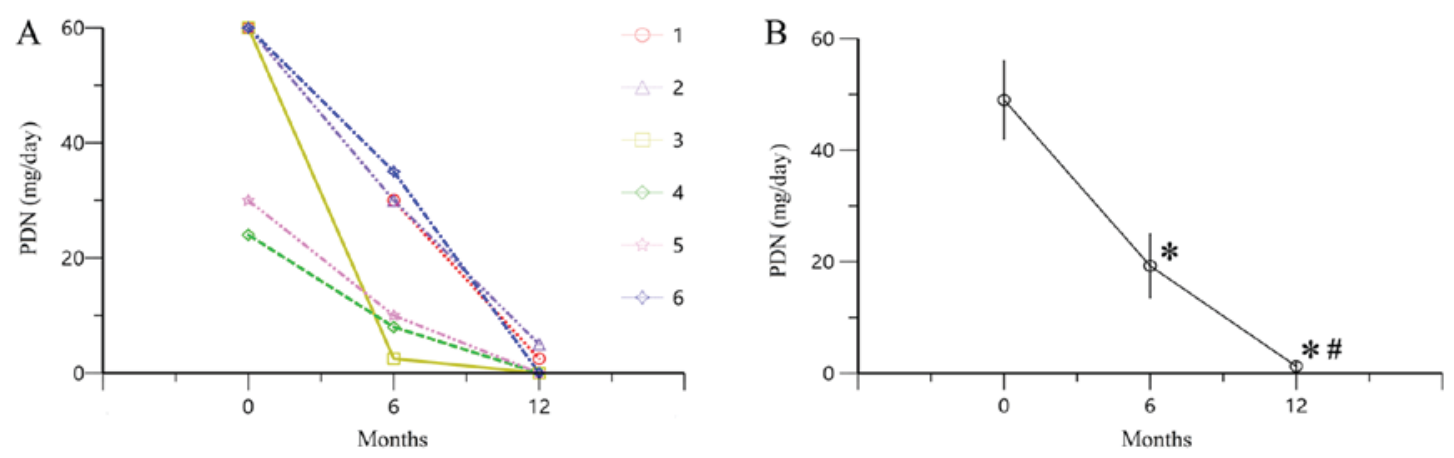

Figure 3. Changes in PDN dose following treatment with TAC. (A) Alterations in PDN dose administered to each patient. (B) Mean \pm SE values of PDN dose. ${ }^{*} \mathrm{P}<0.05$ vs. 0 months and ${ }^{\#} \mathrm{P}<0.05$ vs. 6 months. PDN, prednisolone; 0 months, data obtained prior to treatment with TAC; 6 months, data obtained at 6 months of treatment with TAC; 12 months, data obtained at 12 months of treatment with TAC; TAC, tacrolimus.

administration of TAC significantly decreased the expression levels of IL-6 in patients with SOJIA.

\section{Discussion}

A proportion of patients with SOJIA continue to require long-term corticosteroid therapy for disease control. However, repeated and prolonged steroid therapy increases the risk of obesity, cushingoid appearance, hypertension, growth retardation, osteoporosis, infections and psychological problems (13). Therefore, a safe and effective therapeutic strategy for controlling SOJIA is required (14).

Previous studies have identified the importance of suppressing the pathogenic effects of IL-6 and other proinflammatory cytokines in treating SOJIA (14-16). TAC effectively suppresses the production of TNF- $\alpha$, IL-1 $\beta$ and IL- 6 through T cell activation $(9,12)$, and has been successfully used without serious adverse effects to treat rheumatoid arthritis in adults and the elderly patients $(8,9)$. Therefore, it was hypothesized that TAC may be safe and effective to treat SOJIA.

In the current study, it was identified that TAC could significantly downregulate the high ESR, CRP, PLT and WB levels in patients with SOJIA. The dose of the concomitantly administered PDN was gradually reduced during the 12 months of treatment with TAC. The current study indicated that TAC may reduce the required PDN dose and may be an effective treatment strategy for SOJIA.

The mechanism by which TAC effectively ameliorates SOJIA requires further investigation. Previously, the successful use of recombinant homolog of IL-6 receptor antagonist (IL-6Ra), which competitively inhibits binding of IL-6 to the IL-6 receptor, has been reported in the treatment of SOJIA $(14,17)$. The studies verified that IL-6 is a therapeutic target in SOJIA $(14,17)$. In the current study, it was identified that TAC effectively suppresses IL-6 production; therefore, this may be the mechanism by which TAC exerts its therapeutic effects in SOJIA.

Furthermore, previous studies have reported the use of TAC for the treatment of patients with SOJIA. Shimizu et al (18) reported a case of a 6-year-old Japanese female who presented with a 6-month history of polyarthritis and was diagnosed with poly-JIA. This study identified TAC as a potential alternative when treating patients with refractory polyarticular JIA (18). In addition, Tanaka et al (19) reported using TAC to treat difficult cases of SOJIA, including an 8.5-year-old Japanese male with a 6-year history of SOJIA, and a 5-year-old Japanese female with a 1.5-year history of refractory SOJIA. However, these studies both focused on Japanese children. To the best of our knowledge, this is the first study to report the treatment of SOJIA with TAC in Chinese children, including three males and three females, whose duration of disease ranged from 1.1 to 5.0 years.

In conclusion, TAC may be an effective treatment strategy for patients with SOJIA. However, the current study was performed at a single center. Therefore, further multicenter and prospective studies with a larger number of patients are required.

\section{Acknowledgements}

Not applicable.

\section{Funding}

The present study was supported by Clinical Pharmacy Key Specialty Construction Project of Shanghai (grant no. YZ2017/5) and Wuxi Science and Technology Development Guidance Plan (Medical and Health Care; grant no. CSZON1744).

\section{Availability of data and materials}

The datasets used and/or analyzed during the current study are available from the corresponding author on reasonable request.

\section{Authors' contributions}

ZL and DW conceived and designed the study. DW and XC collected and analyzed data. DW and XC wrote the paper. All authors read and approved the final manuscript.

\section{Ethics approval and consent to participate}

The study was approved by the Research Ethics Committee of Children's Hospital of Fudan University. All procedures performed in studies involving human participants were in accordance with the ethical standards of the institutional and/or national research committee and with the 1964 Declaration of 
Helsinki and its later amendments or comparable ethical standards. Informed consent was obtained from all parents/legal guardians of the participants included in the study.

\section{Patient consent for publication}

Not applicable.

\section{Competing interests}

The authors declare that they have no competing interests.

\section{References}

1. Schulert GS, Minoia F, Bohnsack J, Cron RQ, Hashad S, Kon EPI, Kostik M, Lovell D, Maritsi D, Nigrovic PA, et al: Effect of biologic therapy on clinical and laboratory features of macrophage activation syndrome associated with systemic juvenile idiopathic arthritis. Arthritis Care Res (Hoboken) 70 409-419, 2018.

2. Cimaz R: Systemic-onset juvenile idiopathic arthritis. Autoimmun Rev 15: 931-934, 2016.

3. Allantaz F, Chaussabel D, Stichweh D, Bennett L, Allman W Mejias A, Ardura M, Chung W, Smith E, Wise C, et al: Blood leukocyte microarrays to diagnose systemic onset juvenile idiopathic arthritis and follow the response to IL-1 blockade. J Exp Med 204: 2131-2144, 2007.

4. Quartier P, Allantaz F, Cimaz R, Pillet P, Messiaen C, Bardin C, Bossuyt X, Boutten A, Bienvenu J, Duquesne A, et al: A multicentre, randomised, double-blind, placebo-controlled trial with the interleukin-1 receptor antagonist anakinra in patients with systemic-onset juvenile idiopathic arthritis (ANAJIS trial). Ann Rheum Dis 70: 747-754, 2011.

5. de Benedetti F, Massa M, Robbioni P, Ravelli A, Burgio GR and Martini A: Correlation of serum interleukin- 6 levels with joint involvement and thrombocy tosis in systemic juvenile rheumatoid arthritis. Arthritis Rheum 34: 1158-1163, 1991.

6. DeWitt EM, Kimura Y, Beukelman T, Nigrovic PA, Onel K, Prahalad S, Schneider R, Stoll ML, Angeles-Han S, Milojevic D, et al: Consensus treatment plans for new-onset systemic juvenile idiopathic arthritis. Arthritis Care Res (Hoboken) 64: 1001-1010, 2012.

7. Vastert SJ, de Jager W, Noordman BJ, Holzinger D, Kuis W, Prakken BJ and Wulffraat NM: Effectiveness of first-line treatment with recombinant interleukin-1 receptor antagonist in steroid-naive patients with new-onset systemic juvenile idiopathic arthritis: Results of a prospective cohort study. Arthritis Rheumatol 66: 1034-1043, 2014.
8. Kawai S and Yamamoto K: Safety of tacrolimus, an immunosuppressive agent, in the treatment of rheumatoid arthritis in elderly patients. Rheumatology (Oxford) 45: 441-444, 2006.

9. Kondo H, Abe T, Hashimoto H, Uchida S, Irimajiri S, Hara M and Sugawara S: Efficacy and safety of tacrolimus (FK506) in treatment of rheumatoid arthritis: A randomized, double blind, placebo controlled dose-finding study. J Rheumatol 31: 243-251, 2004.

10. Segarra A, Vila J, Pou L, Majo J, Arbos A, Quiles T and Piera LL: Combined therapy of tacrolimus and corticosteroids in cyclosporin-resistant or -dependent idiopathic focal glomerulosclerosis: A preliminary uncontrolled study with prospective follow-up. Nephrol Dial Transplant 17: 655-662, 2002.

11. Suzuki K, Tsugawa K and Tanaka H: Tacrolimus for the treatment of focal segmental glomerulosclerosis resistant to cyclosporine A. Pediatr Nephrol 21: 1913-1914, 2006.

12. Mok CC, Tong KH, To CH, Siu YP and Au TC: Tacrolimus for induction therapy of diffuse proliferative lupus nephritis: An open-labeled pilot study. Kidney Int 68: 813-817, 2005.

13. Hahn D, Hodson EM, Willis NS and Craig JC: Corticosteroid therapy for nephrotic syndrome in children. Cochrane Database Syst Rev: Cd001533, 2015.

14. Tanaka H, Tsugawa $K$, Nakahata T, Suzuki $K$ and Ito E: Leukocytapheresis for the treatment of refractory systemic-onset juvenile idiopathic arthritis. Clin Rheumatol 26: 1014-1016, 2007.

15. Kimura Y, Pinho P, Walco G, Higgins G, Hummell D, Szer I, Henrickson M, Watcher S and Reiff A: Etanercept treatment in patients with refractory systemic onset juvenile rheumatoid arthritis. J Rheumatol 32: 935-942, 2005.

16. Quartier P, Taupin P, Bourdeaut F, Lemelle I, Pillet P, Bost M, Sibilia J, Kone-Paut I, Gandon-Laloum S, LeBideau M, et al: Efficacy of etanercept for the treatment of juvenile idiopathic arthritis according to the onset type. Arthritis Rheum 48: 1093-1101, 2003.

17. Yokota S: Interleukin 6 as a therapeutic target in systemic-onset juvenile idiopathic arthritis. Curr Opin Rheumatol 15: 581-586, 2003.

18. Shimizu M, Ueno K, Ishikawa S, Tokuhisa $\mathrm{Y}$, Inoue $\mathrm{N}$ and Yachie A: Treatment of refractory polyarticular juvenile idiopathic arthritis with tacrolimus. Rheumatology (Oxford) 53: 2120-2122, 2014.

19. Tanaka H, Tsugawa K, Suzuki K, Oki ES, Nonaka K, Kimura S and Ito E: Treatment of difficult cases of systemic-onset juvenile idiopathic arthritis with tacrolimus. Eur J Pediatr 166: 1053-1055, 2007.

This work is licensed under a Creative Commons Attribution-NonCommercial-NoDerivatives 4.0 International (CC BY-NC-ND 4.0) License. 